\title{
Review
}

Adam Szulkin ${ }^{a}$, Tünde Szatmári ${ }^{a}$, Anders Hjerpe and Katalin Dobra*

\section{Chemosensitivity and resistance testing in malignant effusions with focus on primary malignant mesothelioma and metastatic adenocarcinoma}

DOI 10.1515/pap-2016-0013

Received July 11, 2016; accepted August 22, 2016

\begin{abstract}
Cell based chemosensitivity and resistance testing is an attractive approach that offers functional measurement of drug response ex vivo with the ultimate goal to guide the choice of chemotherapy for various cancers. Thus, it has a great potential to select patients for the optimal treatment option, thereby offering a tool for personalized cancer therapy.
\end{abstract}

Despite several decades of intensive scientific efforts exvivo tests are still not incorporated in the standard of care. Limited access to fresh tumor tissue, unsatisfactory models and single readout as endpoint constitute major hindrance. Thus, establishing and validating clinically useful and reliable model systems still remains a major challenge.

Here we present malignant effusions as valuable sources for ex-vivo chemosensitivity and resistance testing. Accumulation of a malignant effusion in the pleura, peritoneum or pericardium is often the first diagnostic material for both primary malignant mesothelioma and a broad spectrum of metastatic adenocarcinoma originating from lung-, breast-, ovary- and gastro-intestinal organs as well as lymphoma.

In contrast to biopsies, in these effusions malignant cells are easily accessible and often abundant. Effusion derived cells can occur dissociated or forming threedimensional papillary structures that authentically recapitulate the biology of the corresponding tumor tissue and offer models for ex vivo testing. In addition, effusions

\footnotetext{
adam Szulkin and Tünde Szatmári contributed equally to the paper. *Corresponding author: Katalin Dobra, Division of Pathology, Department of Laboratory Medicine, Karolinska Institutet, Stockholm, Sweden, E-mail: katalin.dobra@ki.se

Adam Szulkin, Tünde Szatmári, Anders Hjerpe, Division of Pathology, Department of Laboratory Medicine, Karolinska Institutet, Stockholm, Sweden
}

have the advantage of being available prior to or concurrent with the pathological review, thus constituting an excellent source of viable cells for simultaneous molecular profiling, biomarker analysis and for establishing primary cells for studying tumor biology and resistance mechanisms.

For a reliable test, however, a careful validation is needed, taking into account the inherited heterogeneity of malignant tumors, but also the complex interplay between malignant and benign cells, which are always present in this setting.

Keywords: adenocarcinoma, chemosensitivity, malignant effusion, malignant mesothelioma, resistance

\section{Background}

\section{Mechanisms of effusion formation and its clinical management}

The pleural and peritoneal cavity normally contains an evenly distributed thin layer of fluid that functions as a protective barrier and as lubricant to minimize friction between the serosal layers. This fluid contains glycosaminoglycans such as hyaluronan, which is synthesized and secreted by mesothelial cells [1]. The volume of this fluid is regulated by the mesothelial cells, together with the migration of proteins and fluids across the serous membrane. Small molecules and water can pass between mesothelial cells by passive diffusion while larger molecules and proteins, are actively transported by pinocytic and cytoplasmic vesicles [2, 3].

When a large amount of fluid is accumulated due to pathological processes it is called an effusion. Under normal conditions the fluid is continuously produced, secreted and reabsorbed. Therefore, a substantial increase in pleural fluid 
production or an inhibition of reabsorption has to occur to yield an increased amount of fluid. Events causing this are lymphatic obstructions caused by malignat tumors, increased microvascular permeability, decreased colloid osmotic pressure and increased capillary venous pressure [4].

An effusion is often the first diagnostic material of a malignant process involving the serosal cavities, i. e., pleura, peritoneum, pericardium and tunica vaginalis testis. The spectrum of malignancies manifested at these locations is broad, comprising primary malignant mesothelioma, advanced metastatic adenocarcinoma of lung-, breast-, ovarian- or gastrointestinal origin and body cavity lymphomas.

Pleural effusion hampers the expansion of the lung, and thereby the ability of the patient to breathe properly. The excess fluid is therefore drained by pleurocentesis in order to ease respiration. This fluid is also the prime source to establish the etiology and the diagnosis. The presence of a primary malignant mesothelioma (MM) or a metastatic adenocarcinoma is revealed by cytopathology. By using adjuvant analyses clinical cytology can often provide information concerning the origin of the tumor and in some cases predict possible therapy effects. In patients with malignant pleural effusion a pleurodesis is often performed to prevent recurrence [5].

The diagnosis of a malignant tumor from effusion involves several different approaches. The cytomorphology in combination with FISH, biomarkers and electron microscopy is adequate in diagnosing $\mathrm{MM}$ and metastatic adenocarcinoma [6-8]. The morphological features and adjuvant methods, indicating MM cells, are well defined in the Guidelines for Cytological diagnosis of epithelioid and mixed type MM [9]. Adherence to the diagnostic criteria delineated in the Guidelines assures a high positive predictive value, meaning that the diagnostic criteria are fulfilled and it should lead to initiation of chemotherapy without delay.

\section{Treatment options and chemotherapy for tumors involving the serosal cavities}

The malignant pleural mesothelioma is in most cases resistant to therapy, and attempts to cure the disease are often associated with significant co-morbidity. The main treatment option for most cases is chemotherapy, however, adjuvant radiotherapy and surgery may reduce local recurrence and prolong survival [10]. The combination of surgery, chemotherapy and radiotherapy in extensive trimodality protocols has shown to improve local tumor control [11-15]. This procedure is, however, associated with substantial co-morbidity, preventing a more general use. The majority of patients present with an advanced disease also when the diagnosis is based on the first effusion and the main remaining therapeutic option for them is chemotherapy.

A systematic review of the literature with meta-analysis gave indication for superiority of combination therapy compared to single agent therapy [16], leading to clinical trials, aiming to find optimal combination therapy for mesothelioma. The standard chemotherapy used for patients with malignant pleural mesothelioma is the combination of a platinum based drug typically cisplatin; combined with the antifolate pemetrexed [17]. In the original study, this treatment increased the survival time compared to patients treated with only cisplatin by 2.8 months, yielding an average survival time of 12.1 months after diagnosis. The response rate was $41 \%$. The increased side effects were suppressed by supplementation of folic acid and vitamin $B_{12}$, which also increased the survival time. A follow up study indicates that a selected group of mesothelioma patients could benefit from a second line treatment [18]. This opens up for new possibilities and intensified search for optimal combination treatment in multiple second line phase II and III trials [19, 20].

Over the years several cytotoxic drug combinations have been evaluated [21, 22] some presenting similar or even better response rates than the standard treatment. Exchanging cisplatin with carboplatin gives similar treatment outcome in patients and has the advantage of fewer side effects [23, 24]. Combining cisplatin with gemcitabine instead of pemetrexed gave varying responses rates, but the average survival time was shorter $[25,26]$. Combining cisplatin with vinorelbine in a small phase II study presented interesting results with an average overall survival time of 16.8 months but these results need to be verified in a larger patient group [27]. Another small phase II study, treating malignant pleural mesothelioma patients with gemcitabine in combination with oxaliplatin, produced results comparable with the standard treatment [28]. Combining carboplatin, liposomized doxorubicin and gemcitabine resulted in a response rate of $32 \%$ and a survival time of 13 months [29]. Carboplatin has been shown to be less toxic than cisplatin and it is used not only in the treatment of patients with mesothelioma but also non-small cell lung cancer and ovarian cancer [30-32]. Resistance to cisplatin and carboplatin however is a major problem.

Similar to MM, the principal therapeutic agents used in lung adenocarcinoma are platinum analogues combined with pemetrexed, taxanes, gemcitabine, vinca alcaloids [33] and bevacizumab. Thus the standard of care for patients with a good performance status is a platinum- 
based doublet therapy, for review see [34, 35]. For patients with advanced and metastatic lung cancer, targeted therapy is also an integrated part of the clinical routine, comprising, epidermal growth factor receptor (EGFR)-, anaplastic lymphoma kinase (ALK)-, c-ros oncogene-1 (ROS1)- and MET inhibitors [36]. The personalized care of these patients implies a strategy of matching the molecular landscape of individual patient to available therapeutic options and to predict the most effective option by means of biomarker detection [37].

The introduction of combination chemotherapy improved also the survival of patients with metastatic breast cancer [38]. Greatest chance for therapy response have patients with no or one prior therapy (40-60\%), whereas the response rate declines after repeated treatments (30\%) [39]. The therapeutic agents used in metastatic disease include anthracyclines, taxanes, vinorelbine, gemcitabine and platinum drugs [39]. Among targeted agents for HER2 + metastatic breast cancer the clinical practice includes trastuzumab (monoclonal antibody) and lapatinib (tyrosine kinase inhibitor), both giving significant gains in overall survival.

The first-line treatment for ovarian carcinoma is a combination of platinum and taxane based regimen. Despite advanced stage, the majority of patients will achieve complete remission initially, but many of them will develop recurrent disease later. The second line treatments have considerable toxicity. This scenario is likely to change in the near future by incorporation of targeted therapies among which anti-angiogenic agents seem to hold great promise [40-43].

Currently, numerous potential novel strategies are in clinical trials both for mesothelioma $[44,45]$ and metastatic adenocarcinoma [46, 47] comprising immunotherapy [48], vaccines and targeted therapy $[49,50]$. A comprehensive review shows that 17 compounds related to inhibition of angiogenesis are currently tested as first line or second line treatment [51]. Targeted treatment options on unselected patient cohorts are unlikely to give sensibly improved survival. However, a phase II trial using Sorafenib as second line treatment after platinum combination identified a subgroup of patients ( $36 \%$ ) with 6 months progress free survival [52, 53].

Together these clinical trials demonstrate the need for more effective treatment for these patients and that apart from the standard treatment option there might be other combinations which will give the best response for the individual patient. This is further supported by results showing that patients responding to treatment have the longest survival time [54]. Recent studies also indicate that treatment outcome might be predicted by immunohistochemical demonstration of biomarkers [55, 56].

Taken together, there is a great need to improve and develop chemotherapy for patients with malignant pleural mesothelioma or secondary adenocarcinoma. Less than $50 \%$ of patients respond to standard chemotherapy and treatment response yields an increased survival time [17, 54]. This highlights the needed to identify patients that are likely to fail to standard treatment options and find suitable chemotherapeutical treatment options for them.

\section{Prognosis}

Generally the prognosis for patients with malignant pleural mesothelioma is poor with a mean survival time from diagnosis ranging between 9-12 months [57, 58]. Patients with neoplasm dominated by epithelioid cells have a better prognosis and a few are long time survivors, surviving several years after their diagnosis. Treatment with standard chemotherapy increases the average survival by three months and longer survival is seen in patients responding to chemotherapy [54]. The prognosis of metastatic tumors involving the serosal cavities is similarly poor, although it depends on type of tumor. The poor survival times depend on the limited rate of tumor response, which motivates the search for tests that may optimize the choice of drugs and drug combinations.

\section{The rationale of predicting drug sensitivity and resistance in malignancies involving the serosal cavities}

A rational and personalized drug selection ideally implies target identification and accurate prediction of sensitivity or resistance to an array of chemotherapeutic agents. This is particularly important for patients with advanced malignant tumors involving the serosal cavities as these patients often have chemotherapy as the only remaining treatment option and have a remarkably poor prognosis with a limited life expectancy. An effusion is often the first diagnostic material of a malignant process involving the serosal cavities and it represents a broad spectrum of malignancies that manifest at these locations. The effusions associated to these malignancies reflect the tumor pathology, biological behavior and disease outcome, thus providing clinically relevant models to study ex vivo drug sensitivity and resistance tests and molecular profiles. 
In contrast to biopsies, malignant cells are easily accessible and often abundant in effusions. Malignant cells are present dissociated and/or forming threedimensional papillary structures that authentically recapitulate the biology of the corresponding tumor tissue and offer models for ex vivo testing. In addition, effusions have the advantage of being available prior to or concurrent with the pathological review, thus constituting an excellent source of viable cells for simultaneous molecular profiling, biomarker analysis and for establishing primary cells for studying tumor biology and resistance mechanisms.

As chemotherapy has often limited effect but has both considerable side effects and cost, it would be beneficial to identify responders and non-responders among patients with tumors involving the serosal cavities before treatment is initiated. For this purpose the development of methods and markers predicting the response becomes increasingly important. A greater and more detailed understanding of tumor characteristics, new drugs and drug combinations based on individual tumor features, can also hopefully improve outcome for patients with malignant pleural effusions.

\section{Methods to measure chemosensitivity and resistance}

Historically, extensive effort has been devoted to assess the in vitro chemosensitivity of various cancer models, with the ultimate goal to accurately predict clinical drug responses for individual patients; for review see [59-63]. The majority of publications report high accuracy for prediction of drug resistance, independent of tumor type, test method and drugs used, whereas drug sensitivity is less reliable [63]. In the present review we focus mainly on the most widely used methods for chemosensitivity and resistance testing, with particular relevance for malignant effusions.

\section{Measurement of cell viability, metabolic activity and DNA content}

The effect of a drug can be measured in different ways (for a brief summary see Table 1). One way is to compare the amounts of living cells in drug-exposed and control

Table 1: Key points, advantages and disadvantages of different methods to measure chemosensitivity and resistance.

\begin{tabular}{|c|c|c|c|c|}
\hline Name & Measures & Key point of the method & Advantage & Disadvantage \\
\hline Viability assay & - The number of cells & $\begin{array}{l}\text { - Cell counting with an exclusion } \\
\text { dye }\end{array}$ & - Direct measurement & - Laborious- subjective \\
\hline $\begin{array}{l}\text { Colorimetric } \\
\text { assays }\end{array}$ & $\begin{array}{l}\text { - The metabolic activity } \\
\text { of cells }\end{array}$ & $\begin{array}{l}\text { - Metabolic conversion of a } \\
\text { product by the cells, } \\
\text { accompanied with change of } \\
\text { color }\end{array}$ & - Easy and fast & $\begin{array}{l}\text { - Indirect } \\
\text { - Except Alamar blue, toxic to } \\
\text { cells }\end{array}$ \\
\hline $\begin{array}{l}\text { Automated high } \\
\text { throughput } \\
\text { confocal } \\
\text { microscopy }\end{array}$ & - Live and dead cells & $\begin{array}{l}\text { - Automated high throughput } \\
\text { confocal microscopy based } \\
\text { method } \\
\text { - Allows simultaneous analysis of } \\
\text { a large number of drugs }\end{array}$ & $\begin{array}{l}\text { - Useful for large scale } \\
\text { drug sensitivity and } \\
\text { resistance screening }\end{array}$ & $\begin{array}{l}\text { - Does not consider the } \\
\text { benign cell component }\end{array}$ \\
\hline Clonogenic assay & $\begin{array}{l}\text { - The ability of cells to } \\
\text { grow and form } \\
\text { colonies }\end{array}$ & $\begin{array}{l}\text { - Single cell suspension is plated } \\
\text { and the growing colonies are } \\
\text { counted }\end{array}$ & $\begin{array}{l}\text { - Distinguishes between } \\
\text { cytostatic and cytotoxic } \\
\text { effects- accurate }\end{array}$ & $\begin{array}{l}\text { - Not suitable for cells which } \\
\text { are unable to form colonies } \\
\text { or low proliferating cells } \\
\text { - Multiple drugs cannot be } \\
\text { tested } \\
\text { - Tumor cells are dissociated, } \\
\text { the effect of extracellular } \\
\text { environment is lost }\end{array}$ \\
\hline $\begin{array}{l}\text { Fluorescence } \\
\text { Activated Cell } \\
\text { Sorting (FACS) }\end{array}$ & $\begin{array}{l}\text { - Apoptosis } \\
\text { - Cell cycle progression } \\
\text { - DNA content of cells }\end{array}$ & $\begin{array}{l}\text { - Annexin/Propidium lodide } \\
\text { staining is combined with tumor } \\
\text { specific immunological staining } \\
\text { - Fluorescent-based assays where } \\
\text { the dye interchalate with double } \\
\text { stranded DNA }\end{array}$ & $\begin{array}{l}\text { - Allows measurement of } \\
\text { cytotoxic effects in a } \\
\text { mixed cell population } \\
\text { - Direct measurement }\end{array}$ & $\begin{array}{l}\text { - Laborious if a large number } \\
\text { of drugs are tested }\end{array}$ \\
\hline
\end{tabular}


cultures. Cell number can be determined by direct cell counting using an exclusion dye. However, it has the disadvantage of being subjective and not really useful in largescale analysis.

An alternative way is to measure metabolic activity colorimetrically. MTT, MTS, XTT or WST- 1 are such assays based on the reduction of tetrazolium salts and use different enzymatic reduction sites and are dependent on various co-products. MTT and related products are reduced by mitochondrial enzymes to formazan dye, which is accompanied by a change in color. WST-1 is reduced to soluble formazan by electron transport across the plasma membrane of living cells [64]. The product can be measured by spectrophotometry and is strictly correlated to the metabolic activity of the cell population and the amount of live cells. By comparing treated cells to control cells, it is possible to calculate the viability of cells after treatment. The disadvantage of the method mainly concerns the uncertainty of the readout. Since the dye measures metabolic activity, a general increase or decrease of this activity can be incorrectly interpreted as proliferation or cell death. Another major drawback is that they are toxic to the cells and are therefore endpoint assays [65].

Alamar blue, another agent used in colorimetric assays, transforms its colour by a redox reaction process. It is not toxic to the cells therefore it has the advantage that the measurements can be repeated, or the cells can be used for subsequent assays. The general major limitation of these assays is that they are indirect assays, they measure the metabolic activity of the cells, which is not always correlated directly with survival, since metabolic activity can vary among cell lines and throughout the life cycle of a cell and also depends on cell density $[64,66]$.

In some studies it was shown that metabolic assays were inappropriate tools to assess cell proliferation in three-dimensional models or even in two-dimensional cultures in case of high cell density [67]. In a high throughput analysis performed on a cell line involving 117 drugs, both MTT and Alamar blue were reliable in identifying in vitro cytotoxic drugs at early stages of drug candidate selection, with Alamar blue being slightly more sensitive [68]. However, there is a risk for possible false positive or negative results caused by inducers and/or inhibitors of metabolic enzymes that are responsible for transformation of cell toxicity end points. With colorimetric assays we also have to consider if the compound to be tested does not interfere with the enzymatic process and the dye; with Alamar blue we have to assure that the dye is not over-reduced in another product, hydroresorufin which is not fluorescent [69].
Another method to determine cell proliferation and to address the above-mentioned disadvantages; is to quantify the DNA content. This method comprises fluorescentbased assays, where Propidium Iodide (PI) or Hoechst dye, interchalate with double stranded DNA, stochiometrically, reflecting the amount of DNA. For primary cells with low mitotic activity, however, more sensitive methods are required. Fluorescent dyes such as CyQuant, PicoGreen or Acridine Orange/Ethidium Bromide ( $\mathrm{AO} / \mathrm{EB})$ proved to be more sensitive. Acridine Orange is a vital dye that stains both live and dead cells and Ethidium Bromide stains only cells that lost membrane integrity. Therefore, viable cells appear uniformly green and dead cells with Ethidium Bromide are orange [70]. The critical issue with DNA-based live/dead assays is that sufficient time has to be allocated after drug treatment of cells to loose their membrane integrity. This depends on the cell type and drug mechanism. It is believed that these dye exclusion assays may be useful in testing cells, which have a slow growth rate in culture.

When comparing the sensitivity of three dyes, PI, Hoechst and PicoGreen, the cyanine dye PicoGreen was found ten times more sensitive than Hoechst or PI and a very small change in cell numbers could be detected [71]. These stains are also used to monitor formation of apoptotic bodies. Comparison of Alamar Blue colorimetric assay to two assays employing DNA content measurement in different malignant cell types showed discrepancies in terms of over-estimation of cell proliferation by the metabolic assay compared to DNA binding fluorophores [64].

With a recently developed automated high throughput confocal microscopy based method; the ex vivo response of various haematological malignancies was measured after exposure to a broad panel of anticancer drugs [72-75]. With this method primary effusion lymphoma-derived cell lines obtained from ascites fluid were tested against 27 frequently used cytostatic drugs. The authors showed that all drugs were active and that all cell lines had a distinct, individual drug sensitivity pattern for clinically used drug concentrations. The celllines showed sensitivity for anti-microtubule drugs and anthracyclins in a heterogenous pattern that indicates that deteremination of drug sensitivity on an individual basis might be justified for these patients [72]. The same method was applied to MM cells and metastatic adenocarcinomas from pleural effusions which were tested for the same panel of chemotherapeutic drugs, having benign effusions as control. The ex vivo drug sensitivity profiles of the patients revealed considerable heterogeneity and individual variability in drug response suggesting 
a need to determine drug sensitivity tests on the primary cells for personalized therapy $[76,77]$. This method is more effective than the WST-1 and PI method; particularly when it comes to large scale drug sensitivity and resistance screening but it does not account for the admixture of benign cells in the studied cell population.

\section{Clonogenic assay}

Clonogenic assays measure the ability of cells to grow and form colonies in monolayer. This method quantifies the ability of drug-exposed cells to divide. Cells are exposed to drugs, after certain exposure time single cell suspension is made and cells are plated at low densities. After several days the colonies are counted and the IC50 values are determined. This method, although accurate, is not suitable for cells, which grow in suspension and there are certain cell types, which although they grow in monolayer, are not able to form colonies from single cells. Compared to colorimetric assays, it has the advantage that it distinguishes between cytostatic and cytotoxic effects. The clonogenic assay was considered for years the "golden standard" to which the other methods were compared for reliability. In a review of several randomized studies based on cloning assay compared to clinician's choice indicate the response rate is significantly higher when the therapy option is selected by the clonogenic assay than when it is selected by a clinician [78].

Consequently, clonogenic assays were widely used on primary cells derived from effusions mainly in '80-s: they were used to test chemosensitivity to cisplatin in ascites and pleural effusion of gastric cancer patients [79]. The result of this in vivo study with intraperitoneal cisplatin administration revealed that all samples except one correlated with the clonogenic assay results. In another study, when tumor cells from five human neoplastic effusions were cloned in soft agar and their sensitivity to anticancer drugs was tested, the in vitro and in vivo results of sensitivity correlated in all samples [80]. Similarly, clonogenic assay was applied on effusions from breast or ovarian cancer patients [81, 82]. In malignant mesothelioma, vinblastine was successfully tested by this assay, and in lung adenocarcinma, the overall sensitivity to bleomycin was found similar in solid tumors and effusions but using the criteria of at least $50 \%$ inhibition at highest dose, only effusions show sensitivity to the drug [83]. In a more recent study, cell lines along with primary cells from effusions of breast cancer patients were tested for several drugs. In this study, clonogenic assay was used along with several other methods to assess the sensitivity of cells to a known drug, trastuzumab and a new antibody-drug conjugate [84].

Over the years, considerable criticism was posed against this method and it was increasingly recognized that it has severe limitations when it comes to the assessment of low proliferating cells [60]. Another major drawback is that multiple drugs cannot be tested by this method. According to several researchers the cell aggregates cannot be clearly distinguished from colonies, but others argue against this (reviewed by [59]). A major theoretical problem would be the fact that the tumor cells are dissociated, and loss of cell interactions, hypoxia, low $\mathrm{pH}$ and three-dimensionality characteristics for in vivo conditions may alter drug response [85]. Since these assays can assess just actively dividing cells, the dormant cells in GO phase of cell cycle are most probably missed by them.

\section{Fluorescence activated cell sorting (FACS)}

An alternative way to measure drug effects in vitro is to use FACS analysis. Using tumor specific immunological reagents, this allows the measurements to be specific for tumor cells. The effect of cytotoxic drugs is best monitored as apoptosis, simultaneously measuring Annexin $\mathrm{V}$ label and uptake of PI. Early in the apoptotic process parts of the cell membrane flips, exposing phosphatidylserine from the inside towards the outer surface of the cell, where Annexin V binds with high affinity. Annexin $\mathrm{V}$ will accumulate on these sites and its immunological demonstration is a sign of early apoptosis. As the apoptosis proceeds, the cell membrane becomes permeable to PI, and the accumulation of both these markers indicates a more advanced cellular damage. This method is useful when studying the apoptotic response in cell populations although some cells don't express phosphatidylserine on the cell surface during early stages of apoptosis [86].

The effects of some drugs are difficult to demonstrate at early time-points, regardless if the analysis is performed colorimetrically or by Annexin V. Drugs aiming at the prevention of angiogenesis can't be expected to have effects in cultures that are independent of blood supply. Furthermore, it seems as if drugs blocking the S-phase will not cause cell death within a short time of exposure. One such example is Pemetrexed (Alimta) [87]. Those effects can, however, be demonstrated by FACS-based cell cycle 
analysis. When the cells are permeabilized to allow uptake of PI, FACS can define the various cell cycle phases based on the nuclear content of DNA. The effect of pemetrexed is consequently seen as S-phase arrest.

A major methodological advantage is the possibility of simultaneous measurement of apoptosis and cell surface phenotype [88-90] that allows identification and tumor specific measurement of apoptosis. A further improvement would be the adaptation of a large scale automated flow cytometry based screening platform that has been successfully used to measure the ex vivo effect of several drugs and their combinations in other cellular contexts [91].

\section{Effusion based models for chemosensitivity and resistance testing}

Screening approaches aiming to fulfill the goal of the personalized cancer medicine are emerging from various model systems employing effusion-derived primary cells, cell-lines and patient effusion derived xenografts (PDX). These models recapitulate the molecular signature of the tumor to varying degree $[92,93]$ and in some cases they have been proved to be predictive of clinical drug response [92, 94].

\section{Chemosensitivity testing of primary cells and short-term cultures derived from malignant effusions}

In a large scale cytotoxicity assay; the effect of 32 commonly used cytotoxic drugs was tested in primary MM cells compared to four benign mesothelial cell isolates obtained from tumor free pleural effusions [75]. Primary cells from patients with MM showed large individual variability in their ex vivo chemosensitivity. Actinomycin D, daunorubicin, taxanes, vinca alkaloids and anthracyclines were the most potent groups of drugs. The most resistant cell isolates were affected by only one drug and the most sensitive ones by ten different drugs. The proportion of malignant cells in the primary cell isolates showed a significant inverse correlation to the proportion of effective drugs and a trend towards correlation with overall survival of the patients was observed. Thus, effusions with a malignant cell content exceeding $45 \%$ showed reduced drug sensitivity and increased resistance toward the most of the tested drugs. This implies a negative correlation between advanced clinical stage and overall drug sensitivity. The study highlighted the need for individual ex-vivo cytotoxicity testing for selecting patients that are likely to respond to the first-line treatment and more importantly offering alternative treatment options for those with a resistance profile towards the first-line treatment. Ex-vivo chemosensitivity testing of primary cells derived from malignant pleural effusion of patients with lung adenocarcinoma showed similar heterogeneity in drug response. Vinblastine, vinorelbine, paclitaxel and actinomycin D were effective in $50 \%$ of the tested primary cells [77], justifying further validation of these finding in clinical settings.

In another study, the chemosensitivity of tumor cells obtained from malignant effusions of the patients with various metastatic carcinomas [94] was investigated by using a simplified titrated thymidine incorporation assay. It was shown that $88 \%$ of the cases were evaluable both for chemosensitivity and clinical correlation. With this approach resistance could be accurately predicted in $82 \%$ and a clinical response in $75 \%$.

Recently, the molecular profile of ascites and pleural effusions was studied and correlated to the in vitro sensitivity profile and to the actual clinical response [93]. The genomic alterations were highly concordant between the primary tumor and patient derived tumor cells isolated from effusion up to 3 weeks from specimen collection, and the sensitivity profile correlated well in cells obtained from pleural effusion with the clinical response. In contrast, the patient derived xenografts (PDX) derived from these cells showed more than 100 allele variants and low correlation with the other samples and consequently less concordance to the primary tumor.

Collectively these data point toward the use of primary effusion derived cells as valid model for drug sensitivity testing. For optimal effect it is essential to minimize the culturing time as culturing cells both in vitro and in vivo causes clonal selection. The cell isolates derived from effusion always contain a mixture of malignant cells, reactive mesothelial cells and inflammatory cells in unknown proportions. To evaluate the proportions of these different cell types is advisable by means of immunocytochemical analysis or FACS sorting and including this parameter in the data interpretation might give important information about the interplay of tumor cells with immune-modulators that can influence the final sensitivity. 


\section{Chemosensitivity testing of patient effusion derived xenografts (PDX)}

Primary cells derived from malignant effusions were recently analyzed in parallel with patient derived xenografts (PDX) obtained by inoculation of the same cells in immunocompromised mice [92, 93]. During in vivo growth a different mutational status emerged and only in $30 \%$ of cases remained the PDX congruent with the primary cells [92]. Cancer cell sensitivity was assessed for standard chemotherapy regimens individually or in combination and in a subset of patients it was possible to establish a correlation between the in vitro drug response and the effect of clinical treatment.

Recently, the efficacy of FAK inhibitors alone or in combination with standard care therapy was tested in a diverse panel of cancer cell lines, in relation to the expression of the NF2 tumor suppressor gene product, Merlin. The results were further validated in mouse xenograft models, and for this, the authors used breast, lung and mesothelioma xenografts all derived from pleural effusions [95].

A major disadvantage of patient derived xenografts compared to primary cells is the selection of sub-clones which in many aspects deviate from the original tumor as reflected by new molecular changes and mutations that arise during this clonal selection [92]. Clonal selection in the PDX model leads to profound differences in the mutational status, underscoring the advantage of primary effusion cells compared to PDX.

\section{Chemosensitivity testing of effusion derived cell-lines in monolayer}

The usefulness of pleural fluids in following the behavior of tumor cells in vitro has long been recognized. Already in 1978, 53 metastatic pleural effusions and 34 cases of mesothelial hyperplasia samples were cultured for up to one year in order to follow their behavior [96]. Effusion derived cell-lines also served in various studies for molecular phenotyping of tumor heterogeneity connected to various differentiation patterns [97-100] followed by sensitivity testing for compounds targeting the identified molecular targets. Thus the proteasome system [87, 101] and the thioredoxin system were tested in a range of mesothelioma cell-lines [87, 102], showing sensitivity for proteasome inhibitors and selenite. Bortezomib targets the $20 \mathrm{~S} \mathrm{P}$ subunit of the proteasome system and treatment affected three of the studied cell lines with further increase in sensitivity when combining with the conventional drugs. After uptake in cells, selenium reacts with thiols, forming reactive oxygen species and inducing oxidative stress, which in turn causes apoptosis [102]. The essential part of this reactivity is demonstrated as decreased drug effect in cells with high expression of antioxidant proteins [103]. The selenite effect is hampered by the addition of antioxidant compounds, resulting in decreased formation of reactive oxygen species [102, 104, 105]. Malignant cells, including drug resistant ones, have been shown to be more sensitive to selenite treatment than benign cells [102, 106-108].

Cell lines derived from pleural effusions were widely used for screening of different drugs and more importantly, to find drug resistance markers and signatures as well as biomarkers predicting individual sensitivity. Our research group has investigated the apoptosis signaling mechanisms after selenite treatment in sarcomatoid and epithelioid mesothelioma cells derived from the pleural effusion of a patient with MM. With this system we delineated pathways of apoptosis signalling in response to selenite, showing differences between epithelioid and sarcomatoid mesothelioma cells, interestingly the sarcomatoid ones being more sensitive to this drug [109]. The same cell lines, along with 4 others were subjected to a broader drug screening, using conventional drugs and two experimental drugs. In addition, the sensitivity to different drugs was correlated to the immunoreactivity of several potential predictive markers (Pgp, MRP-1, ERCC1, RRM1, TS, xCT and proteasome 20S subunit). We found that cells with an epithelioid phenotype are more sensitive to the different drugs than the sarcomatoid cells. The studied cell lines were generally unaffected by treatment with doxorubicin, gemcitabine or carboplatin, but in different combinations, however, significant synergistic effects were induced by doxorubicin. This mirrors the clinical situation were treatment with a single drug is ineffective and drug combinations yield better results.

Extensive S-phase arrest was seen in pemetrexedsensitive cell lines. MRP-1 was shown to be a good predictive marker for carboplatin sensitivity whereas xCT predicted the sensitivity for pemetrexed [87]. RRM1 reactivity was verified also in primary cell isolates and it seems to be important for drug sensitivity and survival of the patient. The ability of RRM1 reactivity to predict the effects of drugs has previously been shown in non-small cell lung cancer patients treated with cisplatin and vinorelbine [110]. In repeated pleural effusions from the same patient we observed a progressed disease with an increased proportion of malignant cells, RRM1 reactivity and drug resistance. 
As the importance of cancer stem cells emerged in the last years, effusions started to be used in this context as well. Cell lines derived from pleural effusions were used to validate aldehyde dehydrogenase as cancer stem cell marker in MM and to demonstrate the chemoresistance of cancer stem cells, by using it as stem cell marker, together with CD44 [95, 111].

Recently in a prospective, non-randomized, openlabel clinical trial the feasibility of the cancer stem cell's isolation and chemosensitivity assay was evaluated in effusions or tumor tissue of patients who progressed after standard therapy. In vitro sensitivity assays were performed simultaneously with several drugs, on the basis of the previous treatment regimens and the basic molecular aberration of the individual tumors. In addition to sensitivity assays, in this study, cells derived from spheroids were dissociated and immunologically characterized. Overall, the failure rate in isolation of cancer stem cells was higher in tumor biopsies (failure rate: $45 \%$ ) than with malignant effusions (failure rate: $23 \%$ ) [112]. This study shows that testing of cancer stem cell's chemosensitivity is feasible in the clinical setting and neoplastic effusion samples are the most suitable for this purpose, thus providing a new personalized therapeutic option.

Similar to PDX, a limiting factor with established celllines is however, that the selection pressure over time with sub-sequent cell culturing will lead to clonal selection which thereby might have a profound influence on the outcome of the sensitivity testing.

\section{Chemosensitivity testing of effusion derived cell-lines in three dimensional spheroid system}

Three-dimensional models established from primary cells or cell lines established from malignant effusions or tissue samples constitute a more complex system. This allows sensitivity markers to be checked in conditions that better resemble the clinical situation with welldeveloped cell-cell contacts. Generally, these models exhibit high multicellular resistance, which may model the resistance of the actual parental tumor. These models could be also helpful in explaining the discrepancies between in vitro studies and their therapeutic applicability. For example, the role of the PI3K/Akt/mTOR pathway $[113,114]$ and autophagy [115] in drug resistance of MM tumors and the involvement of autophagy in sensitizing tumor cells was studied in this system.
Histoculture drug response assay (HDRA) is an anticancer drug sensitivity test using 3-dimensional culture, growing cells on gelfoam, and then applying a colorimetric assay such as MTT. Its big disadvantage is the requirement for a large number of cells and the influence of surrounding fibroblasts also has to be considered. It was successfully applied for example in testing lung cancer cells. It was even achieved a prolonged overall survival by a treatment using an HDRA-sensitive regimen [116]. It was also applied for testing the chemosensitivity of the ascites derived tumor cells from patients with gastric and colorectal cancer, in order to establish the optimal dose for intraperitoneal therapy. The cells were cultured using a three-dimensional culture matrix of thermoreversible gelation polymer, allowing spheroid formation, followed by drug treatment and quantitation of viable cells by a formazan assay. The drug was administered to the patients at a dose calculated to achieve ascitic fluid drug levels equivalent to the IC 50 to a group of sensitive patients and a group of resistant patients. They observed that both the median survival time and the median time to progression were significantly longer in the sensitive patients [117].

The collagen gel droplet embedded culture drug sensitivity test (CD-DST) is a new in vitro anticancer drug sensitivity test based on proliferation measurements which allows the analysis of a small number of cells, in contrast to other anticancer drug sensitivity test like HDRA. It is also a 3-dimensional culture that resembles the body environment and it is not affected by adjacent fibroblasts, and thus has high predictive value. Technically it is a simple colorimetric assay where neutral red staining is used in collagen gel drops that are imaged on a video-microscope.

CD-DST was applied for a panel of 9 chemotherapeutic drugs on biopsies of pleural MM, the data marginally correlated to the actual effect of chemotherapy in these patients [118]. A certain extent of clinical usefulness of CD-DCT for lung, colon or breast cancer and stomach cancer was also found [119-122]. When CD-DST was used to analyze the cytotoxic effect of chemotherapeutic drugs using ascites and pleural fluid samples of ovarian cancer patients $[123,124]$ the results correlated well with clinical outcomes. These results suggest that CD-DST is more useful for ovarian cancer when evaluating the anticancer drug sensitivity of malignant cells in ascites and pleural fluids than in evaluating primary tumors.

Cancer stem cell sensitivity assays are a new approach of studying the effects of cytotoxic drugs, since the cancer stem cells represent a population of immature tumor cells that are particularly resistant to chemotherapy. 
Tumor cells are isolated from biopsies or effusions and kept under specific culture conditions, which selects the immature tumor cells that express markers of stemness. These cells are then exposed to the drugs in vitro. Recent studies showed that this type of sensitivity assay based on cancer stem cells can be a useful tool in a clinical setting as well. The report also argues for the use of pleural effusion because of the easy collection anyway required for relief of symptoms and with its low co-morbidity. The sample type was the most important factor for the success of the method and percentage of patients benefitting from the test [112].

\section{Genome wide screening combined with biological chemotherapy response profiles}

New studies emerged where the sensitivity testing is combined with genome wide analysis of cells derived from tissue samples or pleural effusions of patients. A high throughput drug screen using a panel of targeted therapeutic agents was combined with extensive whole exome sequencing and transcriptome profiling of pleural MM cell lines and primary early passage cells. A subgroup of mesotheliomas demonstrated high sensitivity to FGFR inhibition. Loss of BAP1 could be associated with this sensitivity, being a potential biomarker for FGFR inhibitor efficacy [125].

A novel resistance signature to pemetrexed/carboplatin treatment was established by microarray analysis of samples derived from a long-term survivor mesothelioma patient, analyzing biopsies before and after developing drug resistance [126]. The results indicate that changes in the metabolism of pyrimidine and purine are central in this development of resistance. The value of measuring thymidylate synthase (TS) protein expression and not mRNA in response to treatment was seen in these experiments.

In another study bioinformatics analysis of the microarray data of 53 pleural MMs paired with normal tissue revealed that the mitotic spindle assembly checkpoint pathway and cytoskeleton/spindle microtubules network were most significantly altered in these tumors. This analysis was followed by cell viability assays to assess sensitivity to specific small molecule inhibitors targeting microtubules and a nontaxane small molecule inhibitor, epothilone B. Targeting the microtubules was found as a promising potential therapeutic agent; in a similar setting, screening several cell lines for drug sensitivity together with gene expression profiling, osteopontin level was found a suitable biomarker for pemetrexed sensitivity [127].

The increasing number and complex pattern of actionable mutations warrant further improvement of the prediction. Efforts aiming to incorporate multiple parameters and biological pathway information in drug sensitivity prediction algorithms are emerging in several laboratories [128, 129]. To convert these in-vitro data to clinically reliable drug predictions requires, however, accurate validation and it constitutes a bigger challenge. Thus, the scientific community is still struggling to find optimal drug sensitivity algorithms and to match therapeutic interventions to the individual genomic context of each patient.

\section{Implementation of effusions as useful tools for ex-vivo chemosensitivity testing}

As mentioned above, many tumors present with a malignant effusion as first manifestation. The withdrawn fluid will then be the first material available for diagnosis, not only determining whether malignant or not but also providing information such as possible origin and presence of predictive markers.

The tumor cells obtained from fresh effusion can be grown in short term cultures and such primary cells are suitable for ex-vivo sensitivity testing. They often also yield larger amount of tumor cells compared to tumor biopsies. In addition they are suitable for simultaneous molecular profiling and biomarker analysis that could give better guidance for patient stratification. An effusion completely dominated by tumor cells, however, indicates a more advanced tumor with a higher degree of resistance that limits the response rate.

For a better chance for successful chemotherapy guidance; the drug testing should therefore also be possible with effusions that have only sparse malignant cells; representing earlier manifestation of the tumor. The benign cell admixtures in such effusions are mainly macrophages and inflammatory cells (granulocytes and lymphocytes) and admixture of various amounts of benign mesothelial cells. This various components mimic the complex interplay with benign cells and immune- 
modulators. One must, however, be aware of the fact that these benign cells may react to drugs in an unpredictable way in cell culture. This underscores the importance of using tumor cell specific measurements. Different strategies can be used to analyze the tumor specific drug sensitivity in this complex system: 1) tumor cells can be enriched by cell sorting or immunology based magnetic separation or 2) cytotoxicity can be measured in this complex natural environment by multi-parameter fluorescence activated cell-sorting (FACS), addressing immunologically labeled tumor cells.

The testing should be performed on freshly isolated cells or short-term cultures in order to avoid clonal selection of the tumor cells. Such clonal selection may influence the sensitivity profile already after a few passages [130]. The possible in vitro drug exposure time is limited; the most often used time frame being $48-72 \mathrm{~h}$ after cell attachment. This time course often provides shorter exposure time compared to what is obtained in vivo. In order to have a test that discriminates more and less sensitive cell isolates, the tested drug concentrations have to be adjusted, using other concentrations than those estimated in clinical use.

\section{Concluding remarks and future perspectives}

Taken together there is an urgent need for individualized treatment for patients with malignant effusions as the prognosis is poor and the therapeutic window for these patients is very narrow. This can, to a certain extent, be based on results from studying tumor cells from malignant effusions, optimizing the choice of drug combinations. By studying the drug sensitivity of primary tumor cells the optimal treatment strategy for individual patients might be predicted, measuring the tumor specific cell death. Focus should then, preferably, be directed towards the ex-vivo effects of drugs that previously have been evaluated in treatment and therefore are accepted as alternative treatment options and novel targeted therapies. The use of integrative approaches with predictive markers and molecular targets can also be of help, although the translation of preclinical data in clinically useful tests must be further improved. By performing such more detailed studies we might be able to suggest both the best first line treatment and the best alternative in patients that are not responding.
Difficulties in evaluating primary cultures due to admixture of variable amounts and types of benign cells should also be addressed. One possibility is to use of multi-parameter flow cytometry. Such an analysis can be developed to include not only markers for apoptosis and cell cycle arrest, but also differentiate between different cell populations and specifically assess tumor specific cell death along with proteins that are essential to drug resistance. Over time such studies may also help to better explain and understand resistance development in patients. For a reliable test, however, a careful validation is needed, taking into account the heterogeneity of malignant tumors, but also the complex interplay between malignant and benign cells.

Author contributions: All the authors have accepted responsibility for the entire content of this submitted manuscript and approved submission.

Research funding: None declared.

Employment or leadership: None declared.

Honorarium: None declared.

Competing interests: The funding organization(s) played no role in the study design; in the collection, analysis, and interpretation of data; in the writing of the report; or in the decision to submit the report for publication.

\section{References}

1. Heldin P, Pertoft H. Synthesis and assembly of the hyaluronancontaining coats around normal human mesothelial cells. Exp Cell Res 1993;208:422-9.

2. Cotran RS, Karnovsky MJ. Ultrastructural studies on the permeability of the mesothelium to horseradish peroxidase. J Cell Biol 1968;37:123-37.

3. Fedorko ME, Hirsch JG, Fried B. Studies on transport of macromolecules and small particles across mesothelial cells of the mouse omentum. II. Kinetic features and metabolic requirements. Exp Cell Res 1971;69:313-23.

4. Sahn SA. The pathophysiology of pleural effusions. Annu Rev Med 1990;41:7-13.

5. Shaw P, Agarwal R. Pleurodesis for malignant pleural effusions. Cochrane Database Syst Rev 2004;2004:CD002916.

6. Segal A, Sterrett GF, Frost FA, Shilkin KB, Olsen NJ, Musk AW, et al. A diagnosis of malignant pleural mesothelioma can be made by effusion cytology: results of a 20 year audit. Pathology 2013;45:44-8.

7. Dejmek A, Hjerpe A. The combination of CEA, EMA, and BerEp4 and hyaluronan analysis specifically identifies $79 \%$ of all histologically verified mesotheliomas causing an effusion. Diagn Cytopathol 2005;32:160-6.

8. Michael CW, Chhieng D, Bedrossian CWM, editors. Cytohistology of the serous membranes. New York: Cambridge University Press, 2015. 
9. Hjerpe A, Ascoli V, Bedrossian CW, Boon ME, Creaney J, Davidson B, et al. Guidelines for the cytopathologic diagnosis of epithelioid and mixed-type malignant mesothelioma. Complementary statement from the International Mesothelioma Interest Group, also endorsed by the International Academy of Cytology and the Papanicolaou Society of Cytopathology. Acta cytologica 2015;59:2-16.

10. Rusch VW, Rosenzweig K, Venkatraman E, Leon L, Raben A, Harrison L, et al. A phase II trial of surgical resection and adjuvant high-dose hemithoracic radiation for malignant pleural mesothelioma. J Thorac Cardiovasc Surg 2001;122:788-95.

11. Weder W, Stahel RA, Bernhard J, Bodis S, Vogt P, Ballabeni P, et al. Multicenter trial of neo-adjuvant chemotherapy followed by extrapleural pneumonectomy in malignant pleural mesothelioma. Ann Oncol 2007;18:1196-202.

12. Van Schil PE, Baas P, Gaafar R, Maat AP, Van de Pol M, Hasan B, et al. Trimodality therapy for malignant pleural mesothelioma: results from an EORTC phase II multicentre trial. Eur Respir J 2010;36:1362-9.

13. Bolukbas S, Manegold C, Eberlein M, Bergmann T, Fisseler-Eckhoff A, Schirren J. Survival after trimodality therapy for malignant pleural mesothelioma: radical pleurectomy, chemotherapy with cisplatin/pemetrexed and radiotherapy. Lung Cancer 2011;71:75-81.

14. Krug LM, Pass HI, Rusch VW, Kindler HL, Sugarbaker DJ, Rosenzweig KE, et al. Multicenter phase II trial of neoadjuvant pemetrexed plus cisplatin followed by extrapleural pneumonectomy and radiation for malignant pleural mesothelioma. J Clin Oncol 2009;27:3007-13.

15. Elkiran ET, Kaplan MA, Sevinc A, Aksoy S, Demirci U, Seker M, et al. Multicentric study on malignant pleural mesothelioma in Turkey: clinicopathologic and survival characteristics of 282 patients. Med Oncol 2012;29:3147-54.

16. Berghmans T, Paesmans M, Lalami Y, Louviaux I, Luce S, Mascaux C, et al. Activity of chemotherapy and immunotherapy on malignant mesothelioma: a systematic review of the literature with meta-analysis. Lung Cancer 2002;38:111-21.

17. Vogelzang NJ, Rusthoven JJ, Symanowski J, Denham C, Kaukel E, Ruffie P, et al. Phase III study of pemetrexed in combination with cisplatin versus cisplatin alone in patients with malignant pleural mesothelioma. J Clin Oncol 2003;21:2636-44.

18. Manegold C, Symanowski J, Gatzemeier U, Reck M, von Pawel J, Kortsik C, et al. Second-line (post-study) chemotherapy received by patients treated in the phase III trial of pemetrexed plus cisplatin versus cisplatin alone in malignant pleural mesothelioma. Ann Oncol 2005;16:923-7.

19. Buikhuisen WA, Hiddinga BI, Baas P, van Meerbeeck JP. Second line therapy in malignant pleural mesothelioma: A systematic review. Lung Cancer 2015;89:223-31.

20. Maggioni C, Barletta G, Rijavec E, Biello F, Gualco E, Grossi F. Advances in treatment of mesothelioma. Expert Opin Pharmacother 2016;17:1197-205.

21. Fennell DA, Gaudino G, O‘Byrne KJ, Mutti L, van Meerbeeck J. Advances in the systemic therapy of malignant pleural mesothelioma. Nat Clin Pract Oncol 2008;5:136-47.

22. Ellis P, Davies AM, Evans WK, Haynes AE, Lloyd NS. The use of chemotherapy in patients with advanced malignant pleural mesothelioma: a systematic review and practice guideline. J Thorac Oncol 2006;1:591-601.
23. Ceresoli GL, Zucali PA, Favaretto AG, Grossi F, Bidoli P, Del Conte G, et al. Phase II study of pemetrexed plus carboplatin in malignant pleural mesothelioma. J Clin Oncol 2006;24:1443-8.

24. Katirtzoglou N, Gkiozos I, Makrilia N, Tsaroucha E, Rapti A, Stratakos G, et al. Carboplatin plus pemetrexed as first-line treatment of patients with malignant pleural mesothelioma: a phase II study. Clin Lung Cancer 2010;11:30-5.

25. Byrne MJ, Davidson JA, Musk AW, Dewar J, van Hazel G, Buck M, et al. Cisplatin and gemcitabine treatment for malignant mesothelioma: a phase II study. J Clin Oncol 1999;17:25-30.

26. Kalmadi SR, Rankin C, Kraut MJ, Jacobs AD, Petrylak DP, Adelstein DJ, et al. Gemcitabine and cisplatin in unresectable malignant mesothelioma of the pleura: a phase II study of the Southwest Oncology Group (SWOG 9810). Lung Cancer 2008;60:259-63.

27. Sorensen JB, Frank H, Palshof T. Cisplatin and vinorelbine firstline chemotherapy in non-resectable malignant pleural mesothelioma. Br J Cancer 2008;99:44-50.

28. Schutte W, Blankenburg T, Lauerwald K, Schreiber J, Bork I, Wollscgkaeger B, et al. A multicenter phase II study of gemcitabine and oxaliplatin for malignant pleural mesothelioma. Clin Lung Cancer 2003;4:294-7.

29. Hillerdal G, Sorensen JB, Sundstrom S, Riska H, Vikstrom A, Hjerpe A. Treatment of malignant pleural mesothelioma with carboplatin, liposomized doxorubicin, and gemcitabine: a phase II study. J Thorac Oncol 2008;3:1325-31.

30. Calvert AH, Harland SJ, Newell DR, Siddik ZH, Harrap KR. Phase I studies with carboplatin at the Royal Marsden Hospital. Cancer Treat Rev 1985;12:51-7.

31. Sandler A, Gray R, Perry MC, Brahmer J, Schiller JH, Dowlati A, et al. Paclitaxel-carboplatin alone or with bevacizumab for nonsmall-cell lung cancer. N Engl J Med 2006;355:2542-50.

32. du Bois A, Luck HJ, Meier W, Adams HP, Mobus V, Costa S, et al. A randomized clinical trial of cisplatin/paclitaxel versus carboplatin/paclitaxel as first-line treatment of ovarian cancer. J Natl Cancer Inst 2003;95:1320-9.

33. Boulikas T, Vougiouka M. Recent clinical trials using cisplatin, carboplatin and their combination chemotherapy drugs (review). Oncol Rep 2004;11:559-95.

34. Bunn Jr PA. Chemotherapy for advanced non-small-cell lung cancer: who, what, when, why? J Clin Oncol 2002;20:23S-33S.

35. Pillai RN, Ramalingam SS. Advances in the diagnosis and treatment of non-small cell lung cancer. Mol Cancer Ther 2014;13:557-64.

36. Rothschild SI. Targeted Therapies in Non-Small Cell Lung Cancer-Beyond EGFR and ALK. Cancers 2015;7:930-49.

37. Kalia M. Biomarkers for personalized oncology: recent advances and future challenges. Metabolism 2015;64:S16-21.

38. Ross MB, Buzdar AU, Smith TL, Eckles N, Hortobagyi GN, Blumenschein $G R$, et al. Improved survival of patients with metastatic breast cancer receiving combination chemotherapy. Cancer 1985;55:341-6.

39. Johnston SR. The role of chemotherapy and targeted agents in patients with metastatic breast cancer. Eur J Cancer 2011;47:S38-47.

40. Gonzalez-Martin A, Sanchez-Lorenzo L, Bratos R, Marquez R, Chiva L. First-line and maintenance therapy for ovarian cancer: current status and future directions. Drugs 2014;74:879-89. 
41. Petrillo M, Nero C, Amadio G, Gallo D, Fagotti A, Scambia G. Targeting the hallmarks of ovarian cancer: The big picture. Gynecol Oncol 2016;142:176-83.

42. Korkmaz T, Seber S, Basaran G. Review of the current role of targeted therapies as maintenance therapies in first and second line treatment of epithelial ovarian cancer; In the light of completed trials. Crit Rev Oncol Hematol 2016;98:180-8.

43. Marchetti C, Palaia I, De Felice F, Musella A, Donfracesco C, Vertechy L, et al. Tyrosine-kinases inhibitors in recurrent platinum-resistant ovarian cancer patients. Cancer Treat Rev 2016;42:41-6.

44. Schunselaar LM, Quispel-Janssen JM, Neefjes JJ, Baas P. A catalogue of treatment and technologies for malignant pleural mesothelioma. Expert Rev Anticancer Ther 2016;16:455-63.

45. Remon J, Reguart N, Corral J, Lianes P. Malignant pleural mesothelioma: new hope in the horizon with novel therapeutic strategies. Cancer Treat Rev 2015;41:27-34.

46. Shea M, Costa DB, Rangachari D. Management of advanced non-small cell lung cancers with known mutations or rearrangements: latest evidence and treatment approaches. Ther Adv Respir Dis 2016;10:113-29.

47. Zeichner SB, Terawaki H, Gogineni K:A. Review of systemic treatment in metastatic triple-negative breast cancer. Breast Cancer Basic Clin Res 2016;10:25-36.

48. Langer CJ. Emerging immunotherapies in the treatment of nonsmall cell lung cancer (NSCLC): the role of immune checkpoint inhibitors. Am J Clin Oncol 2015;38:422-30.

49. Schramm A, De Gregorio N, Widschwendter P, Fink V, Huober J. Targeted Therapies in HER2-Positive Breast Cancer - a Systematic Review. Breast care 2015;10:173-8.

50. Kempf E, Rousseau B, Besse B, Paz-Ares L. KRAS oncogene in lung cancer: focus on molecularly driven clinical trials. Eur Respir Rev 2016;25:71-6.

51. Christoph DC, Eberhardt WE. Systemic treatment of malignant pleural mesothelioma: new agents in clinical trials raise hope of relevant improvements. Current Opin Oncol 2014;26:171-81.

52. Papa S, Popat S, Shah R, Prevost AT, Lal R, McLennan B, et al. Phase 2 study of sorafenib in malignant mesothelioma previously treated with platinum-containing chemotherapy. J Thorac Oncol 2013;8:783-7.

53. Sweeney CJ, Sandler AB. Treatment of advanced (stages III and IV) non-small-cell lung cancer. Current Prob Cancer 1998;22:85-132.

54. Blayney JK, Ceresoli GL, Castagneto B, O‘Brien ME, Hasan B, Sylvester R, et al. Response to chemotherapy is predictive in relation to longer overall survival in an individual patient combined-analysis with pleural mesothelioma. Eur J Cancer 2012;48:2983-92.

55. Zimling ZG, Sorensen JB, Gerds TA, Bech C, Andersen CB, Santoni-Rugiu E. A biomarker profile for predicting efficacy of cisplatin-vinorelbine therapy in malignant pleural mesothelioma. Cancer Chemother Pharmacol 2012;70:743-54.

56. Ting S, Mairinger FD, Hager T, Welter S, Eberhardt WE, Wohlschlaeger J, et al. ERCC1, MLH1, MSH2, MSH6, and betallltubulin: resistance proteins associated with response and outcome to platinum-based chemotherapy in malignant pleural mesothelioma. Clin Lung Cancer 2013;14:558-67, e553.

57. Abakay A, Abakay O, Tanrikulu AC, Sezgi C, Sen H, Kaya H, et al. Effects of treatment regimens on survival in patients with malignant pleural mesothelioma. Eur Rev Med Pharmacol Sci 2013;17:19-24.

58. Robinson BW, Lake RA. Advances in malignant mesothelioma. N Engl J Med 2005;353:1591-603.

59. Srour EF, Brandt JE, Briddell RA, Leemhuis T, van Besien K, Hoffman R. Human CD34 + HLA-DR- bone marrow cells contain progenitor cells capable of self-renewal, multilineage differentiation, and long-term in vitro hematopoiesis. Blood Cells 1991;17:287-95.

60. Weisenthal LM, Lippman ME. Clonogenic and nonclonogenic in vitro chemosensitivity assays. Cancer Treat Rep 1985;69:615-32.

61. Samson DJ, Seidenfeld J, Ziegler K, Aronson N. Chemotherapy sensitivity and resistance assays: a systematic review. J Clin Oncol 2004;22:3618-30.

62. Morgan MM, Johnson BP, Livingston MK, Schuler LA, Alarid ET, Sung KE, et al. Personalized in vitro cancer models to predict therapeutic response: challenges and a framework for improvement. Pharmacol Ther 2016. pii: S0163-7258(16)30078-X. doi: 10.1016/j.pharmthera.2016.05.007. [Epub ahead of print] Review.

63. Volm M, Efferth T. Prediction of Cancer Drug Resistance and Implications for Personalized Medicine. Front Oncol 2015;5:282.

64. Quent VMC, Loessner D, Friis T, Reichert JC, Hutmacher DW. Discrepancies between metabolic activity and DNA content as tool to assess cell proliferation in cancer research. J Cell Mol Med 2010;14:1003-13.

65. Berridge MV, Herst PM, Tan AS. Tetrazolium dyes as tools in cell biology: new insights into their cellular reduction. Biotechnol Annu Rev 2005;11:127-52.

66. Lopez-Barcons LA. Serially heterotransplanted human prostate tumors as an experimental model. J Cell Mol Med 2010;14:1385-95.

67. Ng KW, Leong DTW, Hutmacher DW. The challenge to measure cell proliferation in two and three dimensions. Tissue Eng 2005;11:182-91.

68. Hamid R, Rotshteyn Y, Rabadi L, Parikh R, Bullock P. Comparison of alamar blue and MTT assays for high throughput screening. Toxicol in Vitro 2004;18:703-10.

69. O‘Brien J, Wilson I, Orton T, Pognan F. Investigation of the Alamar Blue (resazurin) fluorescent dye for the assessment of mammalian cell cytotoxicity. Eur J Biochem 2000;267:5421-6.

70. Mironova EV, Evstratova AA, Antonov SM. A fluorescence vital assay for the recognition and quantification of excitotoxic cell death by necrosis and apoptosis using confocal microscopy on neurons in culture. J Neurosci Methods 2007;163:1-8.

71. Blaheta RA, Kronenberger B, Woitaschek D, Weber S, Scholz M, Schuldes $\mathrm{H}$, et al. Development of an ultrasensitive in vitro assay to monitor growth of primary cell cultures with reduced mitotic activity. J Immunol Methods 1998;211:159-69.

72. Otvos R, Skribek H, Kis LL, Gloghini A, Markasz L, Flaberg E, et al. Drug sensitivity patterns of HHV8 carrying body cavity lymphoma cell lines. BMC Cancer 2011;11:441.

73. Skribek H, Otvos R, Flaberg E, Nagy N, Markasz L, Eksborg S, et al. Chronic lymphoid leukemia cells are highly sensitive to the combination of prednisolone and daunorubicin, but much less to doxorubicin or epirubicin. Exp Hematol 2010;38:1219-30.

74. Flaberg E, Sabelstrom P, Strandh C, Szekely L. Extended Field Laser Confocal Microscopy (EFLCM): combining automated 
Gigapixel image capture with in silico virtual microscopy. BMC Med Imaging 2008;8:13.

75. Markasz L, Kis LL, Stuber G, Flaberg E, Otvos R, Eksborg S, et al. Hodgkin-lymphoma-derived cells show high sensitivity to dactinomycin and paclitaxel. Leukemia Lymphoma 2007;48:1835-45.

76. Szulkin A, Otvos R, Hillerdal CO, Celep A, Yousef-Fadhel E, Skribek $\mathrm{H}$, et al. Characterization and drug sensitivity profiling of primary malignant mesothelioma cells from pleural effusions. BMC Cancer 2014;14:709.

77. Otvos R, Szulkin A, Hillerdal CO, Celep A, Yousef-Fadhel E, Skribek $\mathrm{H}$, et al. Drug sensitivity profiling and molecular characteristics of cells from pleural effusions of patients with lung adenocarcinoma. Genes Cancer 2015;6:119-28.

78. Von Hoff DD. He's not going to talk about in vitro predictive assays again, is he?. J Natl Cancer Inst 1990;82: 96-101.

79. Kim HK, Moon H, Lee KS, Moon HS, Kim BS, Kim DJ. Clonogenic assay of gastric adenocarcinoma stem cells--clonogenic assay, stomach cancer. Korean J Intern Med 1987;2:163-9.

80. Ballet F, Petit J, Poupon R, Darnis F. Soft agar clonogenic assay for predicting chemosensitivity of human tumor cells from malignant effusions. Biomedicine 1981;35:177-8.

81. Dittrich C, Dittrich E, Wrba F, Hudec M, Grunt T, Salzer H, et al. Analysis of factors influencing clonogenic growth in vitro of cells from ovarian carcinoma patients. Cancer Lett 1990;50:183-9.

82. Staquet M, Brown Jr BW, Rozencweig M, Van Muylder E, Dodion $P$, Sanders C. Validation of the clinical predictive values of the in vitro phase II clonogenic assay in cancer of the breast and ovary. Am J Clin Oncol 1987;10:485-90.

83. Sikic BIRM, Carter SK, editors. Bleomycin chemotherapy. New York: Academic Press, 1985.

84. Diessner J, Bruttel V, Stein RG, Horn E, Hausler SF, Dietl J, et al. Targeting of preexisting and induced breast cancer stem cells with trastuzumab and trastuzumab emtansine (T-DM1). Cell Death Dis 2014;5:e1149.

85. Miller BE, Miller FR, Heppner GH. Interactions between tumor subpopulations affecting their sensitivity to the antineoplastic agents cyclophosphamide and methotrexate. Cancer Res 1981;41:4378-81.

86. Barrett KL, Willingham JM, Garvin AJ, Willingham MC. Advances in cytochemical methods for detection of apoptosis. J

Histochem Cytochem 2001;49:821-32.

87. Szulkin A, Nilsonne G, Mundt F, Wasik AM, Souri P, Hjerpe A, et al. Variation in drug sensitivity of malignant mesothelioma cell lines with substantial effects of selenite and bortezomib, highlights need for individualized therapy. PLoS One 2013;8:e65903.

88. Dong HP, Kleinberg L, Davidson B, Risberg B. Methods for simultaneous measurement of apoptosis and cell surface phenotype of epithelial cells in effusions by flow cytometry. Nat Protoc 2008;3:955-64.

89. Dong HP, Holth A, Ruud MG, Emilsen E, Risberg B, Davidson B. Measurement of apoptosis in cytological specimens by flow cytometry: comparison of Annexin V, caspase cleavage and dUTP incorporation assays. Cytopathology 2011;22:365-72.

90. Davidson B, Dong HP, Berner A, Risberg B. The diagnostic and research applications of flow cytometry in cytopathology. Diagn Cytopathol 2012;40:525-35.
91. Bennett TA, Montesinos P, Moscardo F, Martinez-Cuadron D, Martinez J, Sierra J, et al. Pharmacological profiles of acute myeloid leukemia treatments in patient samples by automated flow cytometry: a bridge to individualized medicine. Clin Lymphoma Myeloma Leuk 2014;14:305-18.

92. Roscilli G, De Vitis C, Ferrara FF, Noto A, Cherubini E, Ricci A, et al. Human lung adenocarcinoma cell cultures derived from malignant pleural effusions as model system to predict patients chemosensitivity. J Transl Med 2016;14:61.

93. Lee JY, Kim SY, Park C, Kim NK, Jang J, Park K, et al. Patientderived cell models as preclinical tools for genome-directed targeted therapy. Oncotarget 2015;6:25619-30.

94. Akiyoshi T, Wada T, Nakamura Y. Clinical correlations with chemosensitivities measured in a simplified tritiated thymidine incorporation assay in patients with malignant effusion. Oncology 1990;47:418-21.

95. Shapiro IM, Kolev VN, Vidal CM, Kadariya Y, Ring JE, Wright Q, et al. Merlin deficiency predicts FAK inhibitor sensitivity: a synthetic lethal relationship. Sci Transl Med 2014;6:237).

96. Mouriquand J, Mouriquand C, Petitpas E, Mermet MA. Longterm tissue cultures of human pleural effusions: a cytological follow-up. In Vitro 1978;14:591-600.

97. Sun X, Dobra K, Bjornstedt M, Hjerpe A. Upregulation of 9 genes, including that for thioredoxin, during epithelial differentiation of mesothelioma cells. Differentiation 2000;66:181-8.

98. Sun X, Wei L, Liden J, Hui G, Dahlman-Wright K, Hjerpe A, et al. Molecular characterization of tumor heterogeneity and malignant mesothelioma cell differentiation by gene profiling. J Pathol 2005;207:91-101.

99. Dobra K, Andang M, Syrokou A, Karamanos NK, Hjerpe A. Differentiation of mesothelioma cells is influenced by the expression of proteoglycans. Exp Cell Res 2000;258:12-22.

100. Rundlof AK, Fernandes AP, Selenius M, Babic M, Shariatgorji $M$, Nilsonne G, et al. Quantification of alternative mRNA species and identification of thioredoxin reductase 1 isoforms in human tumor cells. Differentiation 2007;75:123-32.

101. Sun X, Gulyas M, Hjerpe A, Dobra K. Proteasome inhibitor PSI induces apoptosis in human mesothelioma cells. Cancer Lett 2006;232:161-9.

102. Nilsonne G, Sun X, Nystrom C, Rundlof AK, Potamitou Fernandes A, Bjornstedt $M$, et al. Selenite induces apoptosis in sarcomatoid malignant mesothelioma cells through oxidative stress. Free Radic Biol Med 2006;41:874-85.

103. Madeja Z, Sroka J, Nystrom C, Bjorkhem-Bergman L, Nordman T, Damdimopoulos A, et al. The role of thioredoxin reductase activity in selenium-induced cytotoxicity. Biochem Pharmacol 2005;69:1765-72.

104. Gandin V, Nystrom C, Rundlof AK, Jonsson-Videsater K, Schonlau F, Horkko J, et al. Effects of the antioxidant Pycnogenol on cellular redox systems in U1285 human lung carcinoma cells. Febs J 2009;276:532-40.

105. Rudolf E, Rudolf K, Cervinka M. Selenium activates p53 and p38 pathways and induces caspase-independent cell death in cervical cancer cells. Cell Biol Toxicol 2008;24:123-41.

106. Husbeck B, Nonn L, Peehl DM, Knox SJ. Tumor-selective killing by selenite in patient-matched pairs of normal and malignant prostate cells. Prostate 2006;66:218-25.

107. Bjorkhem-Bergman L, Jonsson K, Eriksson LC, Olsson JM, Lehmann S, Paul C, et al. Drug-resistant human lung cancer 
cells are more sensitive to selenium cytotoxicity. Effects on thioredoxin reductase and glutathione reductase. Biochem Pharmacol 2002;63:1875-84.

108. Jonsson-Videsater K, Bjorkhem-Bergman L, Hossain A, Soderberg A, Eriksson LC, Paul C, et al. Selenite-induced apoptosis in doxorubicin-resistant cells and effects on the thioredoxin system. Biochem Pharmacol 2004;67:513-22.

109. Nilsonne G, Olm E, Szulkin A, Mundt F, Stein A, Kocic B, et al. Phenotype-dependent apoptosis signalling in mesothelioma cells after selenite exposure. J Exp Clin Cancer Res 2009;28:92.

110. Vilmar AC, Santoni-Rugiu E, Sorensen JB. Predictive impact of RRM1 protein expression on vinorelbine efficacy in NSCLC patients randomly assigned in a chemotherapy phase III trial. Ann Oncol 2013;24:309-14.

111. Cortes-Dericks L, Froment L, Boesch R, Schmid RA, Karoubi G. Cisplatin-resistant cells in malignant pleural mesothelioma cell lines show ALDH(high)CD44(+) phenotype and sphere-forming capacity. BMC Cancer 2014;14:304.

112. D‘Arcangelo M, Todaro M, Salvini J, Benfante A, Colorito ML, D'Incecco A, et al. Cancer stem cells sensitivity assay (STELLA) in patients with advanced lung and colorectal cancer: a feasibility study. PLoS One 2015;10:e0125037.

113. Barbone D, Yang TM, Morgan JR, Gaudino G, Broaddus VC. Mammalian target of rapamycin contributes to the acquired apoptotic resistance of human mesothelioma multicellular spheroids. J Biol Chem 2008;283:13021-30.

114. Wilson SM, Barbone D, Yang TM, Jablons DM, Bueno R, Sugarbaker DJ, et al. mTOR mediates survival signals in malignant mesothelioma grown as tumor fragment spheroids. Am J Respir Cell Mol Biol 2008;39:576-83.

115. Barbone D, Follo C, Echeverry N, Gerbaudo VH, Klabatsa A, Bueno R, et al. Autophagy Correlates with the Therapeutic Responsiveness of Malignant Pleural Mesothelioma in 3D Models. PLoS One 2015;10:e0134825.

116. Yoshimasu T, Oura S, Hirai I, Tamaki T, Kokawa Y, Hata K, et al. Data acquisition for the histoculture drug response assay in lung cancer. J Thorac Cardiovasc Sur 2007;133:303-8.

117. Isogai A, Nagaya M, Matsuoka H, Watanabe T, Tsukikawa S, Kubota S. A new chemosensitivity assay for ascites tumor cells using a thermoreversible gelation polymer as a culture medium and the observed clinical responses. Eur Surg Res 2007;39:41-50.

118. Higashiyama M, Oda K, Okami J, Maeda J, Kodama K, Takami $\mathrm{K}$, et al. In vitro-chemosensitivity test using the collagen gel droplet embedded culture drug test (CD-DST) for malignant pleural mesothelioma: possibility of clinical application. Ann Thorac Cardiovasc Surg 2008;14:355-62.

119. Kawamura M, Gika M, Abiko T, Inoue Y, Oyama T, Izumi Y, et al. Clinical evaluation of chemosensitivity testing for patients with unresectable non-small cell lung cancer (NSCLC) using collagen gel droplet embedded culture drug sensitivity test (CD-DST). Cancer Chemoth Pharmacol 2007;59:507-13.

120. Higashiyama M, Okami J, Maeda J, Tokunaga T, Fujiwara A, Kodama K, et al. Differences in chemosensitivity between primary and paired metastatic lung cancer tissues: In vitro analysis based on the collagen gel droplet embedded culture drug test (CD-DST). J Thorac Dis 2012;4:30-47.

121. Takamura Y, Kobayashi H, Taguchi T, Motomura K, Inaji H, Noguchi S. Prediction of chemotherapeutic response by collagen gel droplet embedded culture-drug sensitivity test in human breast cancers. Int J Cancer 2002;98:450-5.

122. Takebayashi K, Mekata E, Sonoda H, Shimizu T, Endo Y, Tani T. Clinical potential of the anticancer drug sensitivity test for patients with synchronous stage IV colorectal cancer. Cancer Chemoth Pharmacol 2013;72:217-22.

123. Kawaguchi M, Banno K, Susumu N, Yanokura M, Kuwabara Y, Hirao N, et al. Successful analysis of anticancer drug sensitivity by CD-DST using pleural fluid and ascites from patients with advanced ovarian cancer: Case reports. Anticancer Res 2005;25:3547-51.

124. Yabushita H, Ohnishi M, Komiyama M, Mori T, Noguchi M, Kishida T, et al. Usefulness of collagen gel droplet embedded culture drug sensitivity testing in ovarian cancer. Oncol Rep 2004;12:307-11.

125. Alifrangis C, Janssen JQ, Badhai J, Iorio F, Schunselaar L, Kolluri K, et al. High throughput therapeutic screening of malignant pleural mesothelioma (MPM) to identify correlation of sensitivity to FGFR inhibitors with BAP1 inactivation. J Clin Oncol 2015;33.

126. Roe OD, Szulkin A, Anderssen E, Flatberg A, Sandeck H, Amundsen $\mathrm{T}$, et al. Molecular resistance fingerprint of pemetrexed and platinum in a long-term survivor of mesothelioma. PLoS One 2012;7:e40521.

127. Takeuchi S, Seike M, Noro R, Soeno C, Sugano T, Zou F, et al. Significance of osteopontin in the sensitivity of malignant pleural mesothelioma to pemetrexed. Int J Oncol 2014;44:1886-94.

128. Costello JC, Heiser LM, Georgii E, Gonen M, Menden MP, Wang NJ, et al. A community effort to assess and improve drug sensitivity prediction algorithms. Nat Biotechnol 2014;32:1202-12.

129. Khan SA, Faisal A, Mpindi JP, Parkkinen JA, Kalliokoski T, Poso A, et al. Comprehensive data-driven analysis of the impact of chemoinformatic structure on the genome-wide biological response profiles of cancer cells to 1159 drugs. BMC Bioinf 2012;13:112.

130. Szulkin A, Otvos R, Hillerdal CO, Celep A, Yousef-Fadhel E, Skribek $\mathrm{H}$, et al. Characterization and drug sensitivity profiling of primary malignant mesothelioma cells from pleural effusions. BMC Cancer 2014;14:709. 